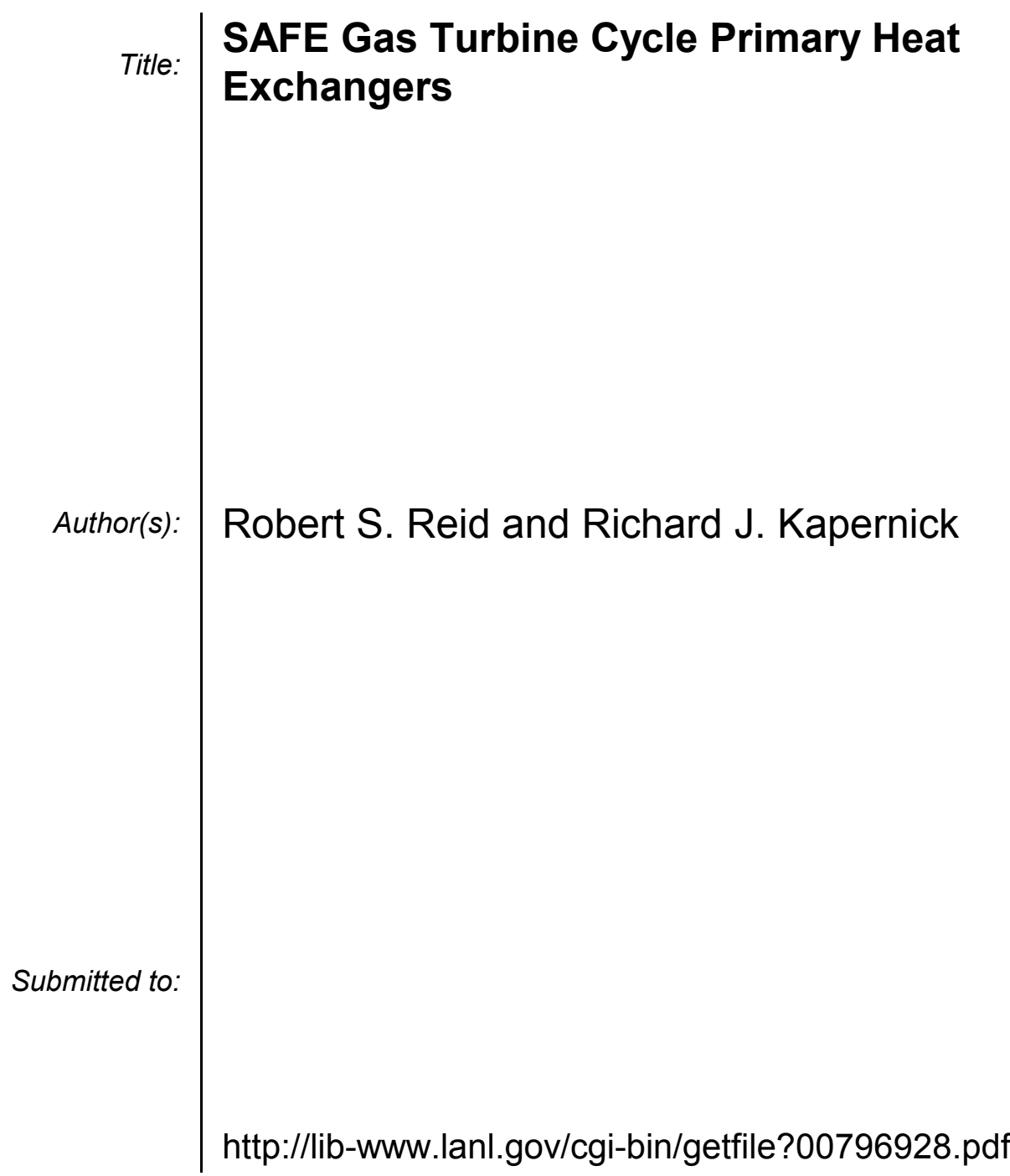

Los Alamos National Laboratory, an affirmative action/equal opportunity employer, is operated by the University of California for the U.S. Department of Energy under contract W-7405-ENG-36. By acceptance of this article, the publisher recognizes that the U.S. Government retains a nonexclusive, royaltyfree license to publish or reproduce the published form of this contribution, or to allow others to do so, for U.S. Government purposes. Los Alamos National Laboratory requests that the publisher identify this article as work performed under the auspices of the U.S. Department of Energy. Los Alamos National Laboratory strongly supports academic freedom and a researcher's right to publish; as an institution, however, the Laboratory does not endorse the viewpoint of a publication or guarantee its technical correctness. 


\title{
SAFE Gas Turbine Cycle Primary Heat Exchangers
}

\author{
Robert S. Reid and Richard J. Kapernick \\ Los Alamos National Laboratory, Los Alamos, NM 87545 \\ (505) 667-2626,FAX:-0600,rsr@lanl.gov
}

\begin{abstract}
Los Alamos National Laboratory and Marshall Space Flight Center are jointly developing two modular heat pipe heat exchangers, collectively named FIGMENT ( $\boldsymbol{F}$ ission $\boldsymbol{I n e r t} \boldsymbol{G}$ as $\boldsymbol{M}$ etal $\boldsymbol{E}$ xchanger for Non-nuclear Testing). The FIGMENT heat exchangers are designed to transfer power from the SAFE nuclear reactor cores to gas turbine energy converters. A stainless steel prototype heat exchanger will be built during 2002 in preparation for the construction of a larger refractory metal version. Two promising FIGMENT stainless steel heat exchanger concepts are reviewed here.
\end{abstract}

\section{INTRODUCTION}

Gas cooling of power-dense nuclear reactor cores can produce large thermal and stress gradients through sensible temperature changes in the coolant. In-core heat pipes remove heat isothermally and reduce the severity of these gradients. The modular SAFE reactor concept consists of numerous heat pipes that permit core reassembly during test and pre-flight integration. The redundancy inherent in the modular heat pipe-based design enhances reactor reliability. The SAFE reactor is designed to operate for extended periods near full power even if several fuel pins or modules fail.

Table 1 lists specifications for the stainless steel and refractory metal versions of the FIGMENT heat exchanger. Sodium heat pipes transfer core power to FIGMENT. A gas mixture, consisting of 70 volume percent helium and 30 volume percent xenon at 2-MPa, absorbs the core power. Three independent gas turbines convert the gas enthalpy into $30 \mathrm{~kW}$ and $100 \mathrm{~kW}$ of electric power for the SAFE 100 and SAFE 300 versions, respectively. A stainless steel FIGMENT will be selected and built during 2002. Heat exchanger effectiveness, structural performance, corrosion, creep, wear, and fatigue will then be characterized. The stainless steel FIGMENT tests will contribute to the design of the refractory metal version of FIGMENT in 2003 and 2004 that will transfer more power at higher temperature.

Gas leaks can potentially limit conversion system life. Although inert gas cannot diffuse through solid metal, leaks may still form through weld joints and cracks when metal expands and contracts with temperature. Adequate seals are essential to control the gas leak rate at high temperature and pressure (Fraas, 1989). Stresses at high-temperature and pressure can limit heat exchanger operating life. FIGMENT will comply with ASME code for a minimum 10,000-hour operating life. Heat pipe heat exchangers often use enhanced surfaces with circular or flat plate fins on a tube array in cross flow (Shah, 1988). Such surfaces generally complicate heat exchanger assembly. Lengthening the heat pipe condenser is used to increase the heat transfer rate avoiding the problems posed by surface enhancement.

Table 1. Heat Exchanger Descriptions.

\begin{tabular}{lrr}
\hline \multicolumn{1}{c}{ Variable } & SAFE 100 & SAFE 300 \\
\hline core energy transfer rate $(\mathrm{kW})$ & 100 & 300 \\
heat pipe number & 61 & 70 \\
heat pipe outside diameter $(\mathrm{cm})$ & 1.59 & 1.59 \\
heat pipe temperature $(\mathrm{K})$ & 973 & 1220 \\
heat exchanger material & 316 stainless steel & niobium \\
gas composition (volume percent) & He $70 \%-$ Xe $30 \%$ & He $70 \%-$ Xe 30\% \\
gas inlet temperature $(\mathrm{K})$ & 655 & 809 \\
gas exit temperature $(\mathrm{K})$ & 953 & 1200 \\
gas pressure $(\mathrm{MPa})$ & 2 & 2 \\
\hline
\end{tabular}




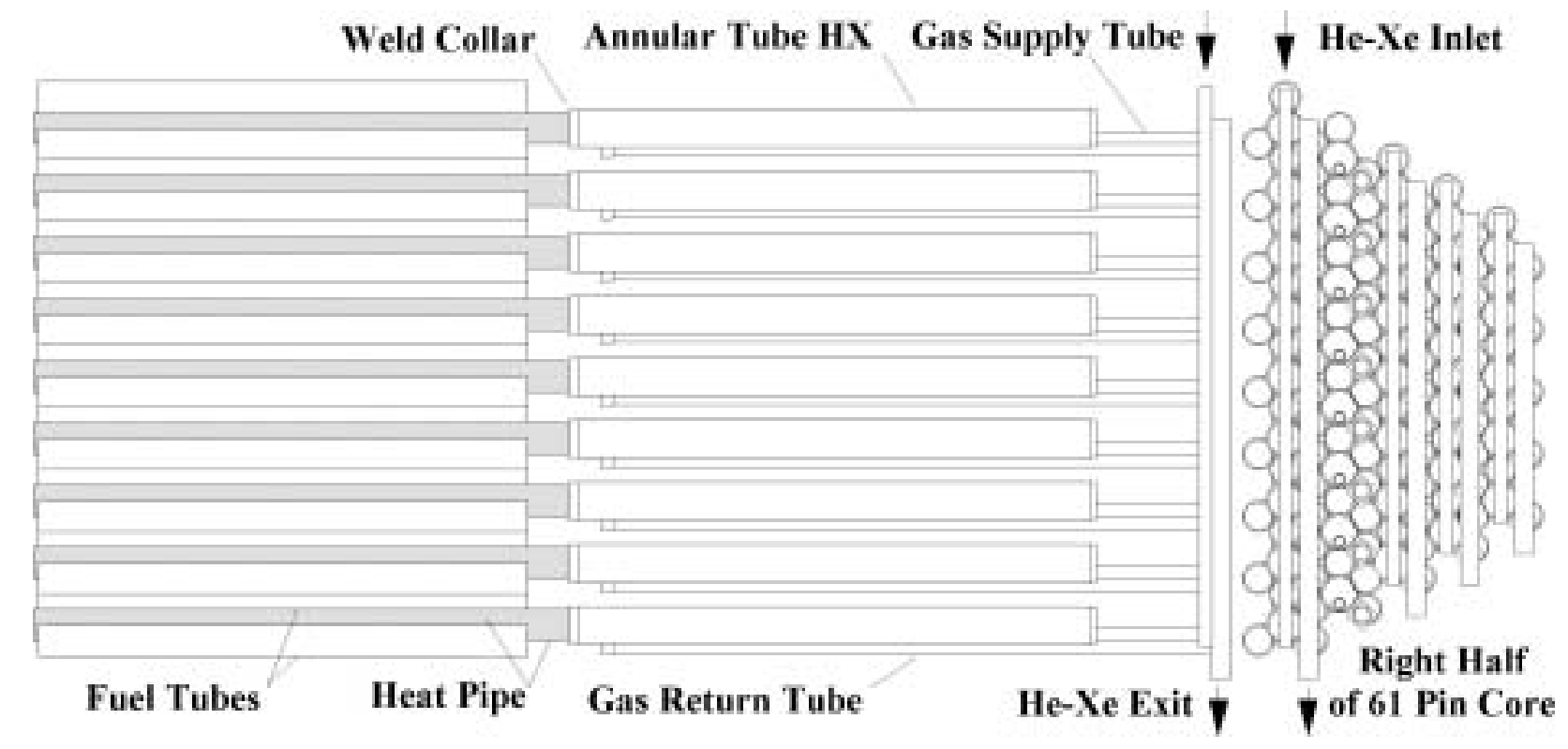

FIGURE 1. Orthogonal Views of the "Shotgun" Annular Heat Exchanger.

\section{ANNULAR HEAT EXCHANGER}

Figure 1 shows orthogonal views of a heat exchanger consisting of an array of annular shells that enclose the heat pipe condensers. The right view looks down on half of a 61-module core. The elements for the 61-module core are arranged on square unit cells. The rendering on the left shows a cross sectional view along the length of the modules. Three fuel tubes are bonded to each of nine heat pipes forming a line of nested modules along the center of the core. A single heat pipe module attached to the annular shell resembles an over-and-under shotgun. This similarity inspired the concept name: "Shotgun" Heat Exchanger. A collar attached to the heat pipe condenser is welded to the annular shell that surrounds the heat pipe. A single attachment point allows the heat pipe to expand freely and reduces thermal stress concentrations in the heat exchanger material.

Gas from a regenerator circulates through manifolds linked to a series of "gas supply tube" branches. A smooth annulus consisting of a $1.59-\mathrm{cm}-\mathrm{OD}$ heat pipe surrounded by a $1.91-\mathrm{cm}-\mathrm{OD}, 0.889-\mathrm{mm}$-thick tube drawn to $1.78-\mathrm{cm}$ OD produces a lightweight, simply-formed shell that tolerates high pressure, high-temperature gas flow. Gas enters the annular space that surrounds each heat pipe condenser. The gas absorbs enthalpy from the heat pipe surface as it flows axially toward the core. Gas exits the annulus and flows through a "gas return tube" into a manifold and is then routed to the turbine.

An annular heat exchanger array permits flow control to individual modules through fixed or variable orifices. Such control can accommodate non-uniform radial heating profiles across the core. Active flow control to individual modules may be necessary to avoid local flow stagnation of gas routed through numerous channels. While individual annular modules are simple to make, connecting all 61 modules to common entrance and exit manifolds presents a difficult, labor-intensive task.

The Reynolds numbers for the SAFE-100 smooth-annulus heat exchanger range $5010<\operatorname{Re}<6547$. Full turbulence for a smooth annulus starts around 7000 making transition region instability a concern for an annular stainless steel heat exchanger. Instability can be avoided with ribs inside the annulus to promote turbulence at lower Reynolds number. Takase (1996) and Takase (2000) correlated data for friction factor and heat transfer in smooth and augmented concentric annular fuel channels used in high temperature helium cooled reactors. Using the Takase correlation an annular heat exchanger with a $20^{\circ} \mathrm{C}$ heat pipe to gas exit temperature difference requires less than $50 \mathrm{~cm}$ length. Square ribs $0.25-\mathrm{mm}$ high wrapped around the heat pipe on a $2.5-\mathrm{mm}$ pitch increase friction factor by a third while reducing the transition Reynolds point below 5000. The Reynolds number range for SAFE-300 heat exchanger is higher: $8767<\operatorname{Re}<11511$ so flow through an annular SAFE-300 heat exchanger should be fully turbulent without ribs. 


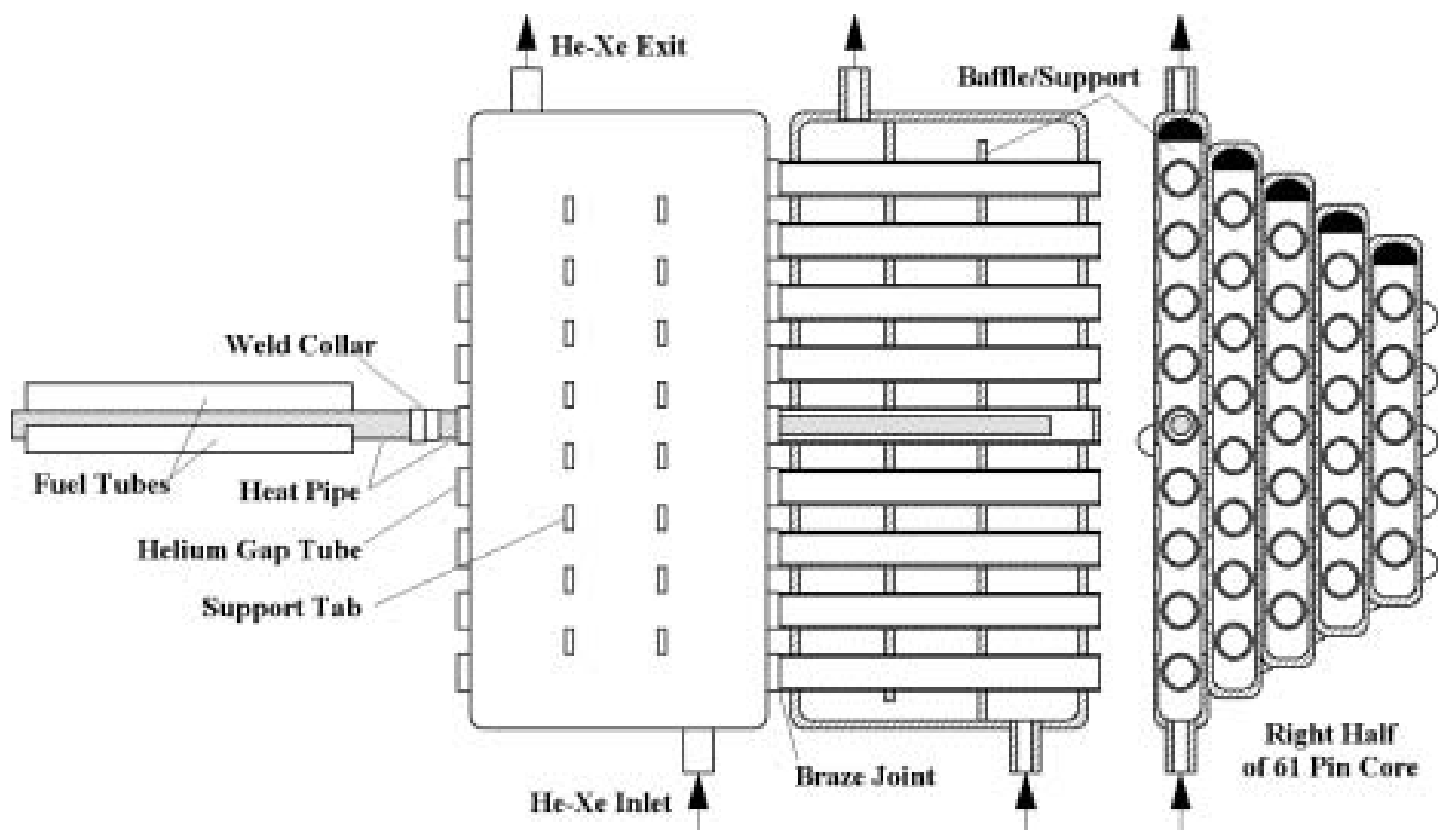

FIGURE 2. Orthogonal Views of "Ritz-Toast" Heat Exchanger Concept.

\section{RITZ TOAST HEAT EXCHANGER}

Heat transfer area is more effectively used in cross flow than in annular flow, but most cross flow ideas proposed so far appear tough to build or do not have an appropriate level of redundancy. Two evolutionary approaches towards the currently favored cross flow concept are called "Ritz Cracker" and "French Toast." The "Ritz Cracker" heat exchanger approach consists of several cylindrical pressure vessels. The entire heat pipe condenser array crosssection passes through the flat faces at the ends of each cylindrical vessel. To visualize the "Ritz Cracker," imagine an array of pins (heat pipes) that pass through two or three Ritz crackers (two or three heat exchanger vessels). Gas flows into each vessel and across the heat pipe array in cross flow. "Ritz cracker" allows the operation of multiple parallel loops. If one of the loops ceases operation, cooling remains uniform across the core.

The "French Toast" heat exchanger approach consists of nine rectangular boxes; each covers a row of heat pipes and spans the entire condenser length. The heat exchanger resembles a stack of French toast of varying lengths placed on end atop the reactor core. Gas circulates in cross flow through a series of baffles in each box. Arranging heat pipe modules in rows eases heat exchanger assembly. However, the large flat surfaces on each box face require considerable reinforcement to avoid high stress concentrations.

Figure 2 shows the "Ritz Toast" heat exchanger. "Ritz Toast" is a hybrid of "Ritz Cracker" and "French Toast." Like "French Toast" a box covers a row of heat pipes. Like the "Ritz Cracker" each heat pipe condenser is enclosed by three heat exchangers. Each heat pipe module is coupled to the gas mixture through an annular gas gap containing stagnant helium at 0.1 MPa enclosed in a sleeve bonded to the heat exchanger (Incropera, 1981). Thermal resistance across the gap depends only on tolerances between the outside diameter of the heat pipe condenser and inside diameter of the sleeve.

Each "Ritz Toast" vessel is individually assembled with its tubes and baffles welded to the shell halves. Once the vessel is complete, adjoining tube banks are aligned and brazed together. The gas gap tubes are then bored to the 
diameter and straightness needed for the heat pipe condenser. The heat pipes are inserted into the gas gap tubes, forming a row of modules. Rows of heat pipe modules are then nested together, forming the core.

"Ritz Toast" is redundant in two directions. Failure of a single heat exchanger only reduces the condenser coupling of one row of modules. The failure of a single heat exchanger does not reduce heat rejection rate from adjacent rows. "Ritz Toast" may be used with more than one gas turbine loops. Alternate rows might be connected to a single gas turbine. Inlet and outlet manifolds are located on the ends of each heat exchanger.

Cross gas flow uses heat transfer area effectively with small attendant pressure drop. Flow stagnation of gas routed across rows should be less troublesome than for the annular flow arrangement. Alternating flow direction with multiple baffles promotes turbulence and flow mixing but increases pressure drop from minor losses and skin friction. Satisfactory heat transfer results have been obtained with nine passes through an in-line bank (Kays, 1984). The flat-faced "Ritz Toast" geometry makes necessary structural support. Support tabs, part of the baffling arrangement, lower stress developed from internal pressure. Additional structural reinforcement will no doubt be needed to extend heat exchanger life toward 100,000 hours.

\section{CONCLUSION}

As of this writing, "Ritz Toast" is favored because of its multiple redundancy levels and relative ease of manufacture. Before heat exchanger construction begins analysis will be conducted to identify and correct any weaknesses in the design approach selected. A thermal math model of the proposed 316 stainless steel "Ritz Toast" SAFE-100 heat exchanger is being assembled for the three heat exchangers passing through the nine-heat pipe row that crosses the core center. A model of the three heat exchangers passing through the five-heat pipe row along the core edge will also be made. A flow distribution scheme consistent with the requirements for the gas turbine system and the core is under development as is an insulation scheme on the outer heat exchanger boundary to keep heat leak within acceptable limits. Analytical relations will be used for the core and gas turbine systems to find the effectiveness of the "Ritz Toast" heat exchanger at the design condition. The analytical results will be incorporated into the thermal math model. The steady state temperature distribution for the five- and nine- heat-pipe-row heat-exchanger structures will be calculated using the design conditions. Some iteration may be required between the analytical and thermal math model calculations.

A finite element structural model of the five- and nine- row "Ritz Toast" heat exchangers will also be built using realistic boundary conditions for the heat exchanger and appropriate symmetry. The steady state temperature results will be used in the structural model to calculate the strain and stress developed in the heat exchanger structure from the internal gas pressure and by expansion from ambient to the design temperature. The stress results will then be compared to 1998 ASME pressure vessel code requirements (e.g., Section III, Division I, NH). The minimum stress to rupture time at temperature will be found. The effects of off-design operation in power, temperature, and pressure on the operating life of the system will also be evaluated. Similar models and analysis will be constructed for a refractory metal SAFE-300 heat exchanger using the SAFE-100 models as a basis.

\section{ACKNOWLEDGMENTS}

This work was supported by NASA Marshall Space Flight Center, Huntsville, Alabama.

\section{REFERENCES}

Fraas, A. P., Heat Exchanger Design Second Edition, Wiley, New York, 1989.

Incropera, F. P., and Dewitt, D. P., Fundamentals of Heat Transfer, Wiley, New York, 1981.

Kays, W. M., and London, A. L., Compact Heat Exchangers, McGraw Hill, New York, 1984.

Shah, R. K., Heat Transfer Equipment Design, Hemisphere Publishing Corporation, New York, 1988.

Takase, K., "Forced Convective Heat Transfer in Square-Ribbed Coolant Channels with Helium Gas for Fusion Power Reactors," Fusion Engineering and Design, 2000, 49-50, pp. 349-354.

Takase, K., "Numerical Prediction of Augmented Turbulent Heat Transfer in an Annular Fuel Channel with Repeated TwoDimensional Square Ribs," Nuclear Engineering and Design, 1996, 165, pp. 225-237. 